\title{
Influence of the longitudinal reinforcement on the shear strength of one-way concrete slabs
}

\author{
Mikel Gurutzeaga ${ }^{a}$, Eva Oller ${ }^{b}$, Carlos Ribas ${ }^{c}$, Antoni Cladera ${ }^{c,}$, Antonio Marí \\ a LKS Ingeniería S.Coop. Goiru Kalea 7, Polo Innovación Garaia, 20500 Arrasate-Mondragón, \\ Gipuzkoa, Spain \\ ${ }^{b}$ Department of Construction Engineering, ETSECCPB - Technical University of Catalonia \\ (UPC). C/Jordi Girona 1-3 Mod C1, 08034 Barcelona, Spain \\ ${ }^{c}$ Department of Physics, University of the Balearic Islands (UIB). Ctra. Vallemossa km 7.5, \\ 07122 Palma, Spain
}

* Corresponding author: University of the Balearic Islands (UIB), Mateu Orfila Building. Ctra. Valldemossa, km 7.5 - 07122 Palma - Spain. Tel: +34 97117 1378. Fax: +34 97117 3426. email: antoni.cladera@uib.es

\begin{abstract}
The shear strength of one-way slabs is studied in this paper via an experimental program performed by the authors and the analysis of a shear test database. The experimental program, in which six slabs and three beams divided into two series were tested, was developed to study the influence of the slab width, the longitudinal reinforcement spacing and the bottom transverse reinforcement on the shear response of one-way slabs. The results showed that the width and the bottom transverse reinforcement do not significantly affect the shear response of the slab. The shear failure surface depends on the longitudinal reinforcement spacing because a three-dimensional resisting mechanism formed as a result of large bar spacing. A database of 79 tests on slabs was analysed to study in depth the influence of these parameters on the shear strength of one-way slabs. Finally, different shear procedures were applied to the database to evaluate their reliability to predict the shear strength.
\end{abstract}

Keywords: reinforced concrete, slab, shear test, shear strength, longitudinal reinforcement spacing. 


\section{INTRODUCTION}

Various two-dimensional members in both building and public work structures can be considered to work unidirectionally for certain support and loading conditions. These structures consist of solid slabs, retaining walls, boxes for underground crossings, caissons used in the construction of docks and piers, slender footings and many other elements. One-way shear is found for distributed loading, close to support lines and even under point loads applied far from the supports. Two-way shear is associated with point loads because shear forces develop radially to introduce the load to the slab. Codes of practice provide several approaches to determine the one- and two-way shear strength of slabs.

Most international concrete standards do not require the incorporation of minimum shear reinforcement for one-way shear slabs as long as the concrete shear strength contribution can withstand the design shear force.

The shear strength of concrete beams with and without shear reinforcement has been broadly studied, although an internationally accepted formulation remains elusive due to the complexity of the problem. As Regan (1993) notes, the most promising analyses have often provided excellent correlations with known results but failed to predict the behaviour in untried circumstances. For simpler models, the problem primarily consists of the need to neglect secondary factors, while secondary factors may act as primary factors in another case.

Moreover, slabs typically require a low amount of longitudinal reinforcement to satisfy the flexural demand (Lubell et al. 2009), especially for large members, as the structural thickness of these members is often sized to avoid the need for shear reinforcement. In light of this reinforcement and the fragile behaviour of concrete under shear, the importance of identifying the influence of the longitudinal reinforcement details on the shear capacity of slabs is evident.

One of the most significant differences between slabs and beams at the sectional level is the transverse spacing of longitudinal reinforcement bars, which can be much higher in slab-type elements than in beams in relation to the member depth. Therefore, the compression struts, which develop from the uncracked compression zone to the longitudinal reinforcement, tend to form in the transverse direction of the slab, and this effect could generate differences in the resistance mechanism. In fact, a three-dimensional state of the stress in the uncracked compression zone could be generated, and the cracking surfaces could be different than in a beam, which could alter the ultimate load of the slab. This phenomenon, exposed at the level of hypothesis, is not sufficiently studied in the technical literature.

To learn more about the shear resistance mechanisms in concrete slabs, an experimental campaign was conducted in two phases with particular emphasis on the spacing of longitudinal reinforcement bars. The first phase consisted of testing four solid slabs and a reference beam, whose main design variables were the spacing of the longitudinal 
reinforcement and the incorporation of bottom transverse reinforcement, also called shrinkage and temperature reinforcement. In this paper, the terms "bottom transverse reinforcement" and "transverse reinforcement" will be indistinctly used. The second phase consisted of a test of two identical slabs and two identical reference beams. The objective of the second phase was to study the robustness of the experimental results.

Moreover, this paper summarise the study of the shear strength of one-way slabs over the past 65 years, the properties of the tested members, the experimental results obtained and a comparison of experimental results obtained for 79 slabs tested by different authors compared with different shear procedure predictions.

\section{ONE-WAY SHEAR STRENGTH IN CONCRETE SLABS}

In 1948, Richart presented the results of an extensive experimental campaign on reinforced concrete wall and column footings (Richart 1948). He observed that the manner of diagonal tension collapse changed from a pyramidal punching failure to the usual inclined diagonal plane across the width of the member, as in a beam, as the proportions of the rectangular footings were varied from the square footing to a long, narrow footing. The dimensions of the rectangular footings tested were $b_{w}=1829 \mathrm{~mm}$ or $b_{w}=1524 \mathrm{~mm}$, with an effective depth, $d$, equal to $254 \mathrm{~mm}$. The $b_{w} / d$ relationship varied from 6.0 to 7.20. Thus, these elements may be considered a perfect slab strip.

In 1962, Diaz de Cossio presented a discussion to demonstrate and comment on the effects of the ratio of the width to depth in rectangular members without web reinforcement, $b_{w} / d$, as this variable was not considered in the development of the ACI equation for shear. This lack of consideration was mostly due to a lack of experimental data that covered an appropriate range of values (Diaz de Cossio 1962). Diaz de Cossio highlighted that most of the tests discussed by the ACI-ASCE Committee 326 concerned components that had width to depth ratios near 0.5. He tested 22 members with widths that ranged from four to eight times the depth, which had depths that were representative of actual slabs. He concluded that the shear strength of a slab is well represented by a nominal shear stress of approximately $0.33 \sqrt{f_{c}^{\prime}}$ (in $\mathrm{MPa}$ ), which was measured at pseudocritical sections situated at $d / 2$ to $0.75 \mathrm{~d}$ from the loaded area. A slight increase in strength should be expected in slabs with steel working in both directions.

The well-known Stuttgart Shear Tests (Leonhardt and Walther 1964), carried out in 1961, also tested 14 slab strips without shear reinforcement. These tests indicated that the shear strength of the slab strips was somehow higher than that of beams, even under concentrated loads. They also studied the relationship between shear strength and the bar diameter for a given percentage of reinforcing steel. The distribution of the reinforcement in the form of closely spaced thin bars was favourable for high tensile steel, not only because of the reduced crack widths but also from the viewpoint of shear strength. 
Kani (Kani et al. 1979) experimentally verified if a narrow beam with $b_{w}$ equal to $254 \mathrm{~mm}$ would behave differently from a four times wider beam $(254 \times 4=1016 \mathrm{~mm})$ if all other parameters were maintained constant. They specifically tested four pairs of beams with different shear span to depth ratios, $a / d$. The wide beams produced results both above and below the results of the beams that were four times narrower. Because the difference never exceeded $10 \%$, the omission of the width from any formula expressing the relative strength of rectangular reinforced concrete beams was apparently justified.

During the 1970s and 1980s, other researchers tested various types of slab strips (Regan and Rezai-Jorabi 1988). For example, Regan and Rezai-Jorabi tested twenty-nine one-way slabs that failed on shear. They tested both concentrated and spread loads, and concluded that the wide-beam shear resistances of slabs can be reduced when loads are concentrated compared to when they are spread over the full width. Furthermore, that the decrease in strength does not generally correspond to the punching failure.

In recent years, this topic has again garnered interest in the research community. In 2004, the results of a large and wide tested beam were presented and confirmed Kani's conclusion, which states that the shear strength of wide beams is directly proportional to the width of the beam (Lubell et al. 2004). The authors of this previous study focused their research on the influence of the size effect and the maximum aggregate size, and concluded that beams without stirrups failed in shear at lower values of shear stress as the members deep increases and the maximum aggregate size decreases. The failure surface of the wide beam tested was the same across the width of the beam, which supported the observation that the failure shear strength is directly proportional to the width of the beam. The width of the beam was $2010 \mathrm{~mm}$, and it was reinforced with No.30M bars at $100 \mathrm{~mm}$.

Sherwood et al. tested nine concrete elements to investigate if the shear provisions may not be conservative when applied to thick slabs or large, wide beams (Sherwood et al. 2006). Once again, the member width was observed to not significantly affect the shear stress at failure for one-way slabs and wide beams. Moreover, the presence of bottom transverse reinforcement did not influence the one-way shear capacity. In this case, $b_{w}$ of all wide beams was equal to $1000 \mathrm{~mm}$, and they were reinforced using $25 \mathrm{M}$ longitudinal bars at $125 \mathrm{~mm}$. Because most slabs in everyday construction do not have shear reinforcement, the size effect could possibly be mitigated by adding short fibres into the concrete (Kragh-Poulsen et al. 2011, Minelli et al. 2013). In addition, these short fibres may delay the occurrence of a shear failure and they may reduce the deflection and crack width (Conforti et al. 2013).

The influence of longitudinal reinforcement on one-way shear in slabs and wide beams was also studied (Lubell et al. 2009). This study empirically demonstrated that the member depth and the longitudinal reinforcement details influence the shear capacity of members without shear reinforcement. Moreover, the member depth and the longitudinal reinforcement could be considered as two independent parameters for one-way shear models. This study also evaluated six shear design models and concluded that shear design 
models that consider the stress (or strain) in the longitudinal reinforcement at the time of shear failure provided a better correlation with the test results. Although the six wide beams tested in this study featured different amounts of longitudinal reinforcement, the transverse spacing of the bars remained practically constant, between 93 and $112 \mathrm{~mm}$.

\subsection{Shear design procedures}

In this paper, the predictions of six shear design procedures are compared with the experimental results. They are the formulations given in Eurocode 2 (European Committee for Standardisation (CEN) 2002), Pérez et al. (Pérez et al. 2010, Pérez et al. 2012), equation 11-3 of ACl318-08 ( $\mathrm{ACl}$ Committee 318 2008), equation 11-5 of ACl318-08 ( $\mathrm{ACl}$ Committee 318 2008) and the two levels of approximations given in Model Code 2010 for components without shear reinforcement (Fédération Internationale du Béton 2012). Table 1 summarises the different shear provisions. Level II of approximation of the Model Code 2010 requires an iterative procedure when applied to experimental data because the term $\varepsilon_{x}$ (Table 1) depends on the bending moment and shear force at the ULS. This procedure does not require iterating when designing new structures.

Any explicit partial safety factor given in the different design formulations has been removed when comparing the predictions with the experimental results, because the objective of this paper is not to carry out a safety calibration, but to study the general response of the presented methods in front of different experimental tests. Average values of the compressive strength have been used for all studied design formulations $\left(f_{c}\right.$ in Table 1). Moreover, the critical section is taken as being placed at a distance $d$ from the applied point loads and $d$ from the support of uniformly loaded specimens, as proposed in (Collins et al. 2008).

\section{EXPERIMENTAL PROGRAM}

An experimental program of two series of one-way slabs without shear reinforcement was developed to study the shear strength under various conditions. Different parameters were analysed, such as the width, the longitudinal rebar spacing and the existence of bottom transverse reinforcement in the tensile zone (Gurutzeaga-Zubillaga 2006).

\subsection{Specimen design}

Series I consisted of four one-way slabs (tested elements I/S) that were $2.4 \mathrm{~m}$ long with a cross-sectional width of $2.0 \mathrm{~m}, 0.25 \mathrm{~m}$ height and a reference beam (tested element l/B) of the same length that had a square cross-section that was $0.25 \mathrm{~m}$ wide and deep. Series II was tested to corroborate the results of Series I and consisted of two one-way slabs (tested elements II/S) that were $2.4 \mathrm{~m}$ long with rectangular cross-sections that were 1.10 $\mathrm{m}$ wide and $0.20 \mathrm{~m}$ deep and two reference beams of the same length (tested elements II/B), with a cross-section that was $0.23 \mathrm{~m}$ wide and $0.20 \mathrm{~m}$ deep. 


\begin{tabular}{|c|c|c|c|}
\hline Shear procedure & \multicolumn{3}{|c|}{ Equation/Variables } \\
\hline $\begin{array}{c}\text { EC-2 } \\
\text { (European Committee for } \\
\text { Standardisation (CEN) } \\
\text { 2002) }\end{array}$ & $\begin{array}{c}\mathrm{V}_{\mathrm{Rd}, \mathrm{c}}=0.18 \\
\mathrm{~V}_{\mathrm{Rd}, \mathrm{Cmin}}=0 \\
k \\
\rho_{l} \\
f_{c}\end{array}$ & $\begin{array}{l}\left.00 \cdot \rho_{\mathrm{l}} \cdot \mathrm{f}_{\mathrm{c}}\right)^{1 / 3} \cdot \mathrm{b}_{\mathrm{w}} \cdot \mathrm{d} \geq \mathrm{V}_{\mathrm{Rd}, \mathrm{c}} \\
\mathrm{x}^{3 / 2} \cdot \mathrm{f}_{\mathrm{c}}{ }^{1 / 2} \cdot \mathrm{b}_{\mathrm{w}} \cdot \mathrm{d} \\
k=1+\sqrt{\frac{200}{d}} \leq 2.00 \\
\text { Geometric amount of the longitudinal } \\
\text { tensile reinforcement } \\
\text { Compressive strength }\left(\mathrm{N} / \mathrm{mm}^{2}\right)\end{array}$ & $\begin{array}{l}\rho_{l}=\frac{A_{S}}{b_{w} \cdot d} \ngtr 0.02 \\
f_{c} \leq 90 \mathrm{MPa}\end{array}$ \\
\hline $\begin{array}{l}\text { Pérez et al. } \\
\text { (Pérez et al. 2010) }\end{array}$ & $\begin{array}{c}\mathrm{V}_{\mathrm{c}}=0.114 \mathrm{k}^{\prime} \\
k^{\prime} \\
\rho_{l} \\
f_{c} \\
V \cdot d / M\end{array}$ & $\begin{array}{l}{ }^{0.37} \mathrm{f}_{\mathrm{c}}^{1 / 3}\left(\frac{\mathrm{V} \cdot \mathrm{d}}{\mathrm{M}}\right)^{0.31} \mathrm{~b}_{\mathrm{w}} \mathrm{d} \\
\text { Size effect; this value is limited to } 4.00 \text {. } \\
\text { In the original equation [16], the value } \\
\text { was limited to } 5.00 \text {, but it was recently } \\
\text { detected that it could produce slightly } \\
\text { conservative results for very small } \\
\text { members. } \\
\text { Geometric amount of the longitudinal } \\
\text { tensile reinforcement } \\
\text { Compressive strength ( } \mathrm{N} / \mathrm{mm}^{2} \text { ) } \\
\text { Shear- moment interaction }\end{array}$ & $\begin{array}{l}k^{\prime}=1+\left(\frac{1600}{d}\right)^{0.42} \leq 4.00 \\
\rho_{l}=\frac{A_{S}}{b_{w} \cdot d} \ngtr 0.08 \\
f_{c} \leq 90 M P a \\
\frac{V \cdot d}{M} \ngtr 1\end{array}$ \\
\hline $\begin{array}{c}A C l 318-08 \\
(\mathrm{ACl} \text { Committee } 318 \text { 2008) }\end{array}$ & $\begin{array}{r}\text { Eq. 11-3: } V_{c}= \\
\text { Eq. 11-5: } V_{c}= \\
\rho_{l} \\
V \cdot d / M \\
f_{c}\end{array}$ & $\begin{array}{l}\sqrt{f_{c}} b_{w} d \\
\left.\sqrt{f_{c}}+17 \rho_{l} \frac{V \cdot d}{M}\right) b_{w} d \ngtr 0.29 \\
\text { Geometric amount of the longitudinal } \\
\text { tensile reinforcement } \\
\text { M occurs simultaneously with } \mathrm{V} \text { at } \\
\text { section considered. } \\
\text { Compressive strength }\left(\mathrm{N} / \mathrm{mm}^{2}\right)\end{array}$ & $\begin{array}{l}b_{c} b_{w} d \\
\rho_{l}=\frac{A_{S}}{b_{w} \cdot d} \\
\frac{V \cdot d}{M} \ngtr 1.0 \\
f_{c} \leq 69 M P a\end{array}$ \\
\hline $\begin{array}{c}\text { MC-2010 } \\
\text { (Féderation International } \\
\text { du Beton 2012) }\end{array}$ & $\begin{array}{r}\mathrm{V}_{\mathrm{Rd}, \mathrm{c}}=\mathrm{k}_{\mathrm{v}} \sqrt{f} \\
k_{v}\end{array}$ & $\begin{array}{l}\text { Level I of approximation: } k_{v}=\frac{1}{1000-} \\
\text { Level II of approximation: } k_{v}=\frac{0 .}{1+15} \\
\text { Factor depending on maximum } \\
\text { aggregate size. For concrete strength in } \\
\text { excess of } 70 \mathrm{MPa} \text {, } \mathrm{d}_{\mathrm{g}} \text { shall be taken as } \\
\text { zero. } \\
\text { Strain effect parameter } \\
\text { Compressive strength }\left(\mathrm{N} / \mathrm{mm}^{2}\right)\end{array}$ & $\begin{array}{c}\frac{25 z}{\varepsilon_{\mathrm{x}}} \frac{1300}{1000+\mathrm{k}_{\mathrm{dgz}}} \\
k_{d g}=\frac{32}{d_{g}+16} \geq 0.75 \\
\varepsilon_{x}=\frac{M / z+V}{2 E_{s} A_{s}} \\
f_{c} \leq 64 M P a\end{array}$ \\
\hline
\end{tabular}

Table 1. Summary of the shear design formulations used in this paper.

In Series I, the percentage of longitudinal reinforcement was very similar between the five different specimens, but the diameter of the bars and the transverse spacing between them were different. In two of the slabs, the internal reinforcement consisted of $7 \phi 25$ bars placed at a transversal distance of $316 \mathrm{~mm}(0.81 \%)$, one with transverse reinforcement (I/S/316/t.r.) and the other one without (I/S/316/0). The remaining two slabs of Series I were reinforced using $17 \phi 16$ bars (0.76\%) with a transversal distance of $119 \mathrm{~mm}$ between them (slab I/S/119/t.r. with transverse reinforcement and slab I/S/119/0 without 
transverse reinforcement). The reference beam (I/B/150/t.r.) was reinforced with $2 \phi 16$ bars at $150 \mathrm{~mm}$ and with transverse reinforcement of $6-\mathrm{mm}$ bars spaced at $200 \mathrm{~mm}$. The transverse reinforcement of the slabs in Series I consisted of 8-mm bars spaced at 200 $\mathrm{mm}$.

Series II consisted of a set of two identical slabs (II/S/250/t.r./A and II/S/250/t.r./B) and two identical reference beams (II/B/65/t.r./A and II/B/65/t.r./B). The percentage of longitudinal reinforcement was identical for the 4 specimens $(0.87 \%)$. For the slabs, the longitudinal reinforcement consisted of $5 \$ 20 \mathrm{~mm}$ bars at $250 \mathrm{~mm}$. For the beams, it consisted of $3 \phi 12 \mathrm{~mm}$ bars at $65 \mathrm{~mm}$. All specimens were provided with transverse reinforcement ( $6 \mathrm{~mm}$ bars at $200 \mathrm{~mm}$ )

Details of all specimens are given in Table 2 and Figures 1-3.

\begin{tabular}{|c|c|c|c|c|c|c|c|c|c|c|c|c|}
\hline Specimen & $\begin{array}{c}b_{w} \\
{[\mathrm{~mm}]}\end{array}$ & $\begin{array}{c}\mathrm{h} \\
{[\mathrm{mm}]}\end{array}$ & $\begin{array}{c}\mathrm{d} \\
{[\mathrm{mm}]}\end{array}$ & $\begin{array}{c}\mathbf{f}_{\mathrm{cm}} \\
{[\mathrm{MPa}]}\end{array}$ & $a / d$ & $\begin{array}{l}\text { Longitud } \\
\text { reinforcer } \\
\text { Bars / } \\
\text { spacing } \\
\text { [mm] }\end{array}$ & $\begin{array}{c}\rho_{\mathrm{l}} \\
(\%)\end{array}$ & Transv. reinf. & $\begin{array}{c}\mathbf{Q}_{\text {failure }} \\
\mathrm{KN}\end{array}$ & $\begin{array}{c}\mathbf{V}_{\text {failure }} \\
\mathbf{k N}\end{array}$ & $\begin{array}{l}\tau_{\text {failure }} \\
\mathrm{MPa}\end{array}$ & $\mathbf{V}_{\text {failure }} / \mathrm{V}_{\mathrm{uEc} 2}$ \\
\hline I/S/316/t.r. & 2000 & 250 & 213 & 37.4 & 2.94 & $7 \phi 25 / 316$ & 0.81 & $\phi 8 / 200$ & 824 & 566 & 1.13 & 1.20 \\
\hline I/S/316/0 & 2000 & 250 & 213 & 37.4 & 2.94 & $7 \phi 25 / 316$ & 0.81 & - & 757 & 521 & 1.04 & 1.11 \\
\hline I/S/119/t.r. & 2000 & 250 & 217 & 37.4 & 2.88 & $17 \phi 16 / 119$ & 0.79 & $\phi 8 / 200$ & 745 & 513 & 1.06 & 1.08 \\
\hline I/S/119/0 & 2000 & 250 & 217 & 37.4 & 2.88 & $17 \phi 16 / 119$ & 0.79 & - & 872 & 600 & 1.20 & 1.27 \\
\hline I/B/150/t.r. & 250 & 250 & 217 & 37.4 & 2.88 & $2 \phi 16 / 150$ & 0.74 & $\phi 6 / 200$ & 94 & 64 & 1.02 & 1.10 \\
\hline II/S/250/t.r./A & 1100 & 200 & 165 & 35.4 & 3.03 & $5 \phi 20 / 250$ & 0.87 & $\phi 6 / 200$ & 368 & 277 & 1.26 & 1.35 \\
\hline II/S/250/t.r./B & 1100 & 200 & 165 & 35.4 & 3.03 & $5 \phi 20 / 250$ & 0.87 & $\phi 6 / 200$ & 373 & 281 & 1.28 & 1.37 \\
\hline II/B/65/t.r./A & 230 & 200 & 169 & 35.4 & 2.96 & $3 \phi 12 / 65$ & 0.89 & $\phi 6 / 200$ & 71.5 & 54 & 1.17 & 1.25 \\
\hline II/B/65/t.r./B & 230 & 200 & 169 & 35.4 & 2.96 & $3 \phi 12 / 65$ & 0.89 & $\phi 6 / 200$ & 70.5 & 53 & 1.15 & 1.23 \\
\hline
\end{tabular}

Table 2. Specimen properties and test results.

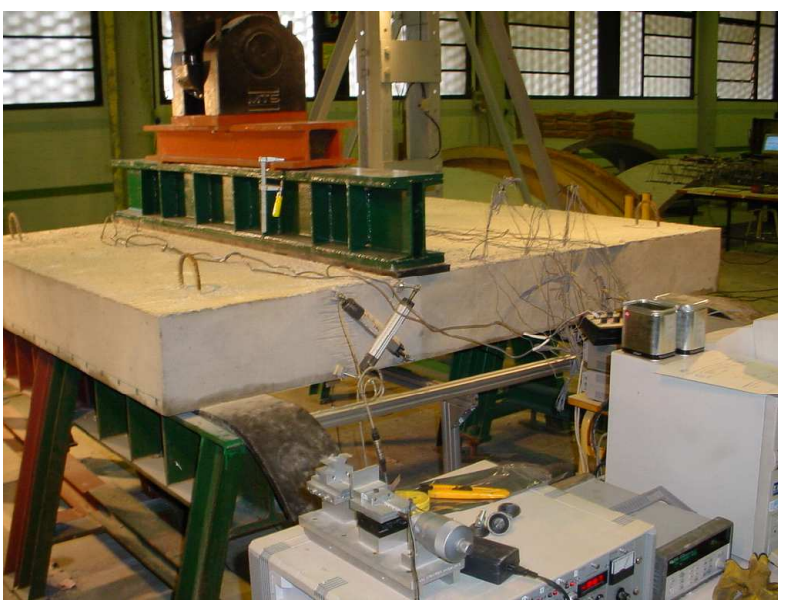

Series I

Figure 1: Test setup for Series I and II.

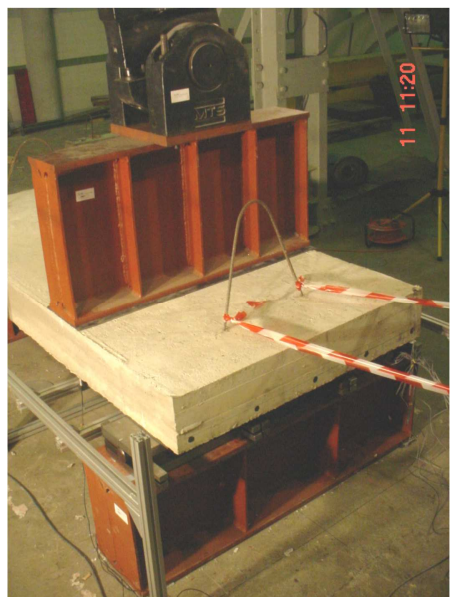

Series II 

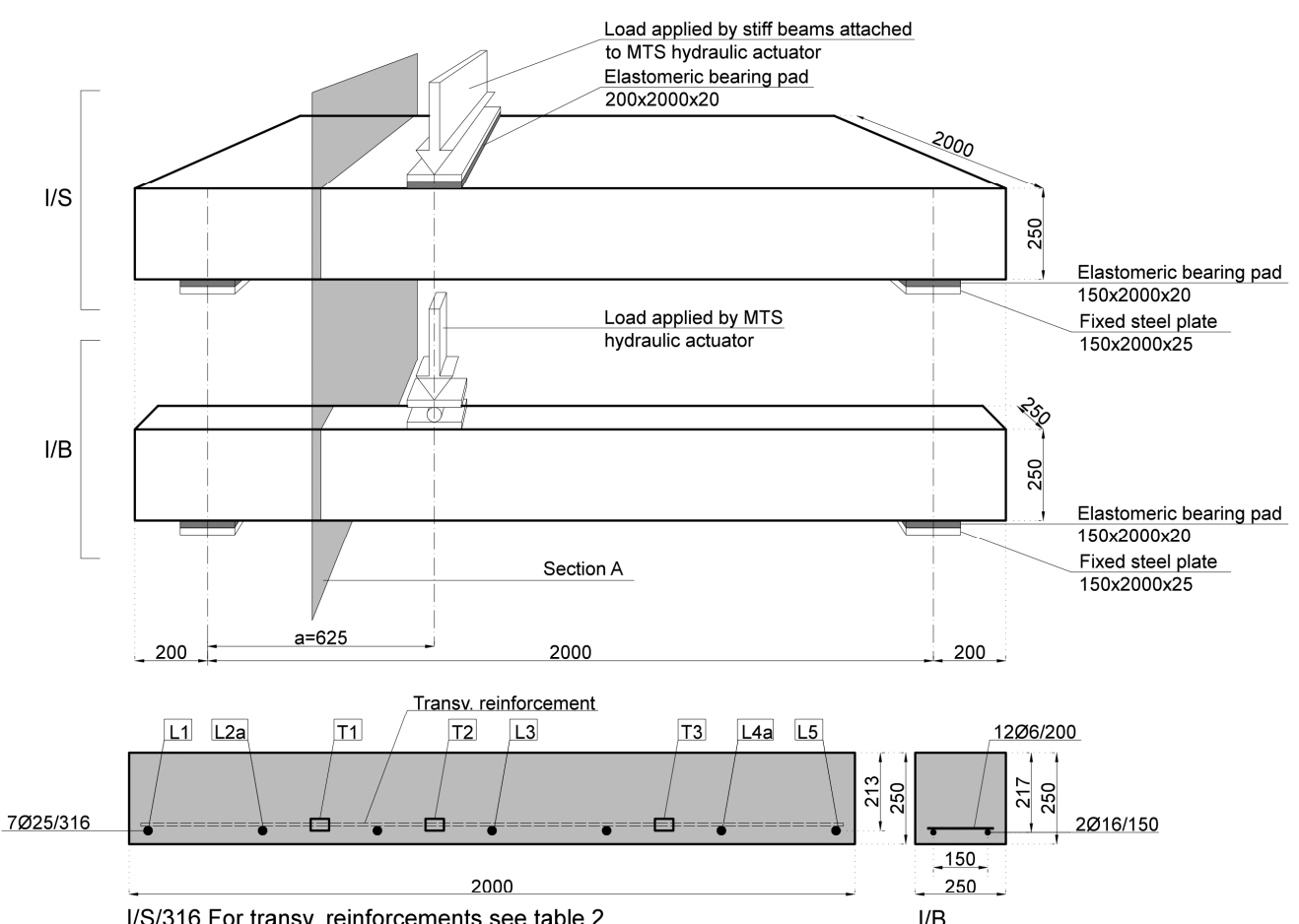

I/S/316 For transv. reinforcements see table 2

l/B

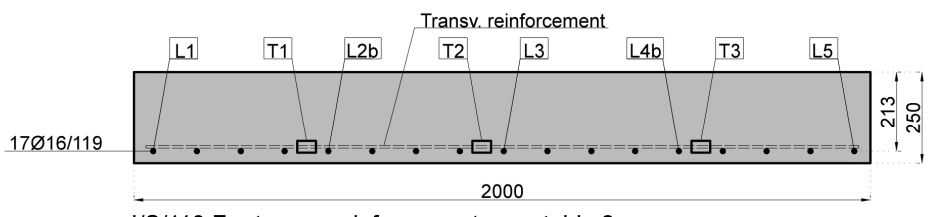

Li : strain gauges

I/S/119 For transv. reinforcements see table 2

Section A

Figure 2: Test setup for Series I elements. Units in $\mathrm{mm}$.

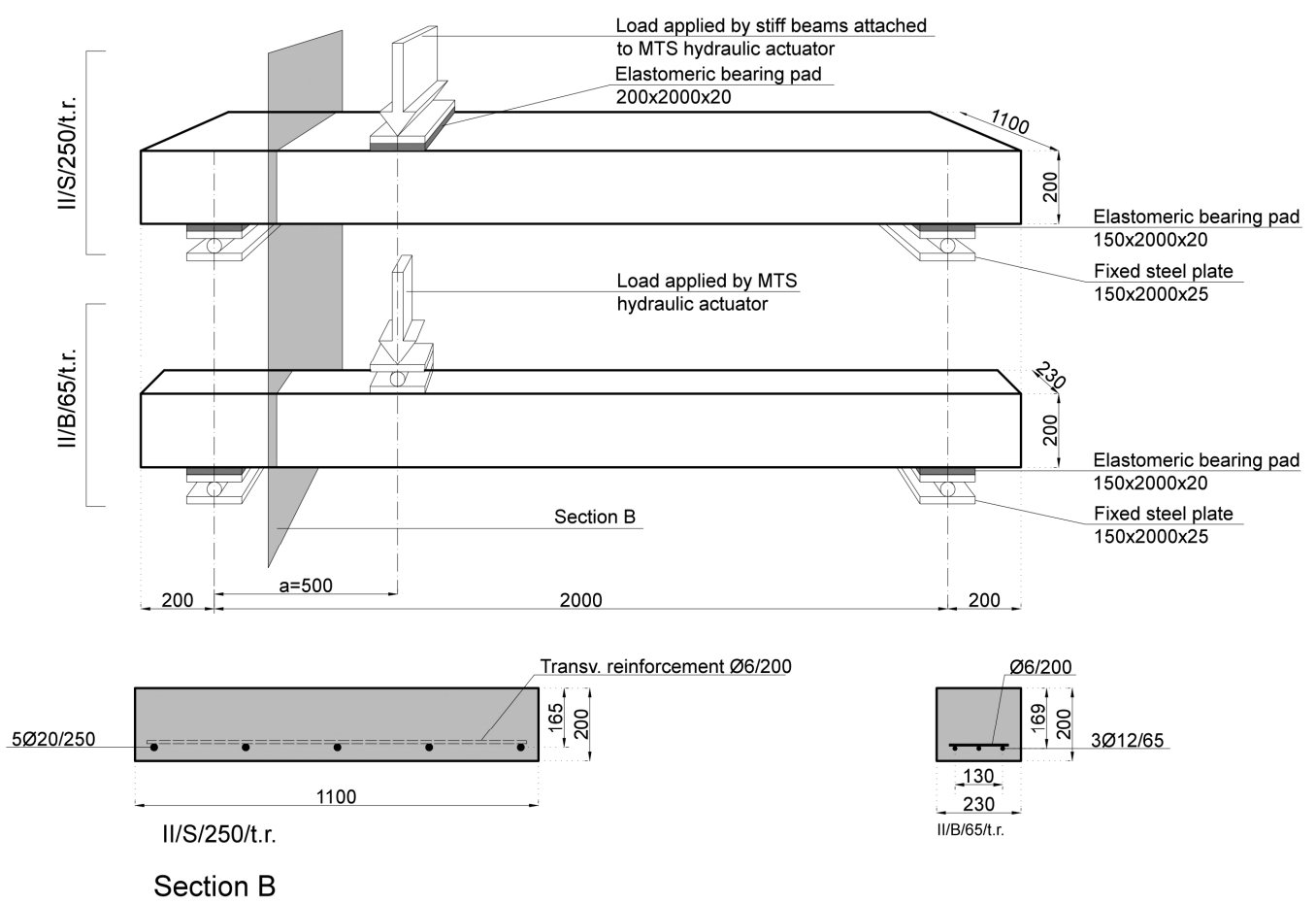

Figure 3: Test set-up for Series II elements. Units in $\mathrm{mm}$. 


\subsection{Materials}

The specimens were cast using a ready-mix concrete from a local supplier with a nominal specified cylinder strength of $25 \mathrm{~N} / \mathrm{mm}^{2}$. The maximum aggregate size was $25 \mathrm{~mm}$ for the specimens of Series I and $20 \mathrm{~mm}$ for Series II. Specimens were moist cured for one week after being cast and then stored in the laboratory until testing after approximately 100 days. Cylinder compression tests were performed to obtain the concrete properties at the age of testing. The compressive strength of Series I was $37.4 \mathrm{~N} / \mathrm{mm}^{2}$ (at 110 days) and 35.4 $\mathrm{N} / \mathrm{mm}^{2}$ of Series II (at 60 days). The modulus of elasticity was also experimentally obtained and yielded values of $30000 \mathrm{~N} / \mathrm{mm}^{2}$ for Series I concrete and $31600 \mathrm{~N} / \mathrm{mm}^{2}$ for Series II.

The internal steel reinforcement consisted of B500S bars of different diameters $\left(f_{y k}=500\right.$ $\mathrm{N} / \mathrm{mm}^{2}$ ).

\subsection{Test configuration}

The simply supported slabs and beams were tested with an effective span of $2.0 \mathrm{~m}$ under a line load configuration using deflection control. The shear span was $625 \mathrm{~mm}$ for Series I and $500 \mathrm{~mm}$ for Series II (Figures 2-3). The support and load elastomeric bearing pads were continuous across the full width of the specimens. The load bearing pads were 200 $\mathrm{mm}$ in width. For slabs of Series I, the support consisted of a $2000 \times 150 \times 20 \mathrm{~mm}$ continuous elastomeric reinforced bearing in an attempt to simulate support at the top of a continuous wall, as shown in Figure 2. The supports of Series I beams also consisted of

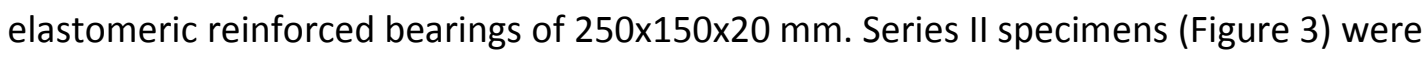
supported on conventional steel rollers with $150 \mathrm{~mm}$ steel bearing plates across the full width of the specimens. The support configuration was changed in Series II to ensure that the arch effect was not significantly affecting the results of Series I.

Stiff beams attached to the loading machine were used to transversely distribute the load, with a different configuration for Series I and II (see Figure 1). The load was applied by means of an MTS hydraulic actuator with a maximum load capacity of $1000 \mathrm{kN}$ and a maximum stroke of $250 \mathrm{~mm}$.

\subsection{Instrumentation}

Electrical strain gauges were embedded in the concrete at multiple positions along the longitudinal and transverse reinforcement as detailed in Gurutzeaga-Zubillaga (2006). Displacement transducers were used to measure the vertical displacements in the slab at the applied load section, at the midspan and under the supports. Finally, transducer displacements were mounted on one side of the beam in a cross configuration to measure average shear strains. 


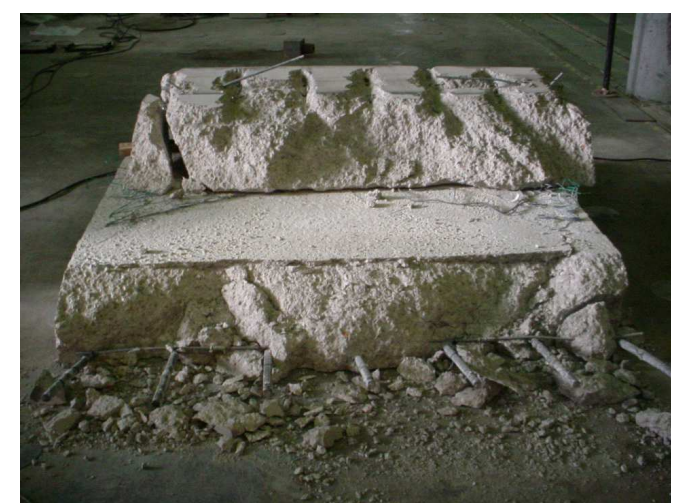

a) $\mathrm{I} / \mathrm{S} / 316 / \mathrm{t} . \mathrm{r}$

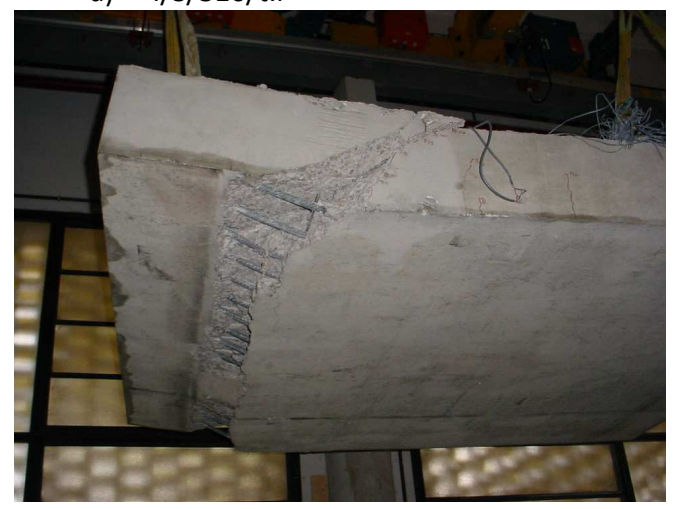

c) $\mathrm{l} / \mathrm{S} / 119 / \mathrm{t} . \mathrm{r}$.

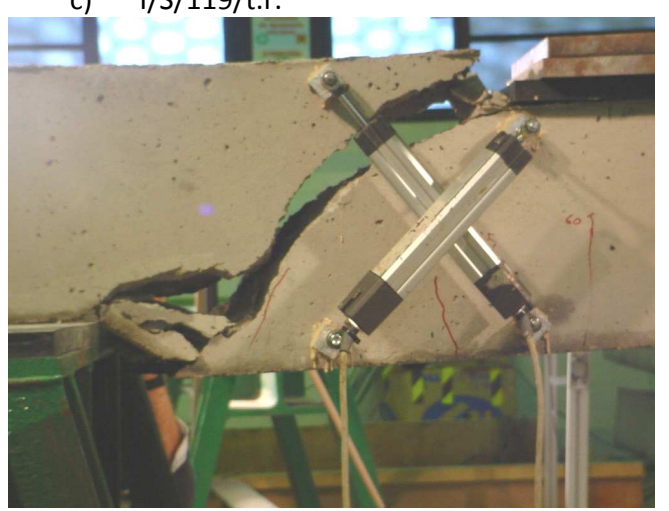

e) $\mathrm{I} / \mathrm{B} / 150 / \mathrm{t} . \mathrm{r}$

Figure 4: Series I specimens. Shear failure surfaces.

\section{EXPERIMENTAL RESULTS AND DISCUSSION}

\subsection{Failure mode}

The results of Series I and II are presented together. A shear failure was observed in all slabs and beams of both series. The difference between them was the form of the shear failure surface. As previously mentioned, all slabs and beams had a similar longitudinal reinforcement ratio; the difference between them was the diameter of the longitudinal reinforcement and the spacing between bars.

In both slabs with a short spacing between the longitudinal bars and in the beams, the shear failure surface was quasi-cylindrical and uniform along the web breadth (see Figure 
$4 c, 4 d, 4 e$, and Figure 5c, 5d). However, in the slabs with a large spacing between bars, the shear failure surface was irregular and curled, with bumps in and out along the web breadth (Figure $4 a, 4 b$ and Figure $5 a, 5 b$ ). This last failure surface could be explained by the formation of a three-dimensional resisting mechanism created by the struts, which are inclined to reach the longitudinal reinforcement. This effect produces an increase of the failure area and of the aggregate interlock effect. As previously mentioned, the support configuration was changed in Series II to verify that these curled surfaces were not related to a possible arch effect due to the continuous elastomeric reinforced bearing simulating a support at the top of a continuous wall that could transmit horizontal forces. However, similar irregular and curled surfaces also appeared in slabs of Series II with a large spacing between bars.

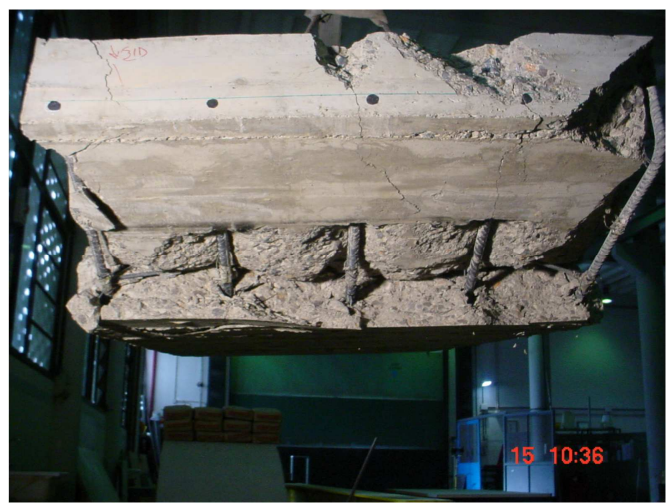

a) $\quad \mathrm{II} / \mathrm{S} / 250 /$ t.r./A

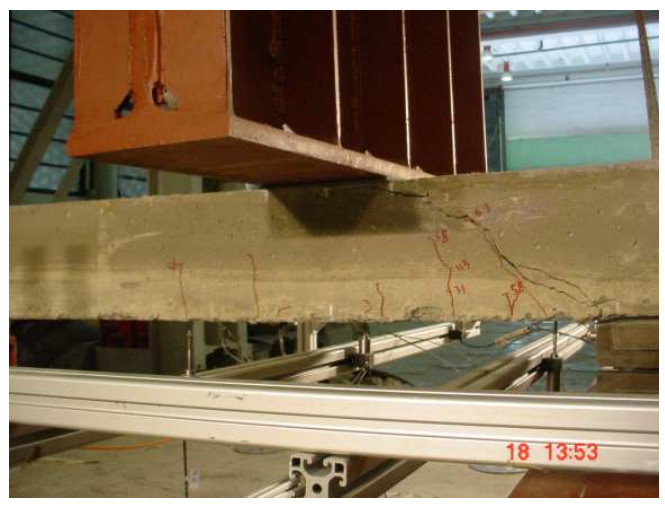

c) $11 / \mathrm{B} / 65 /$ t.r./A

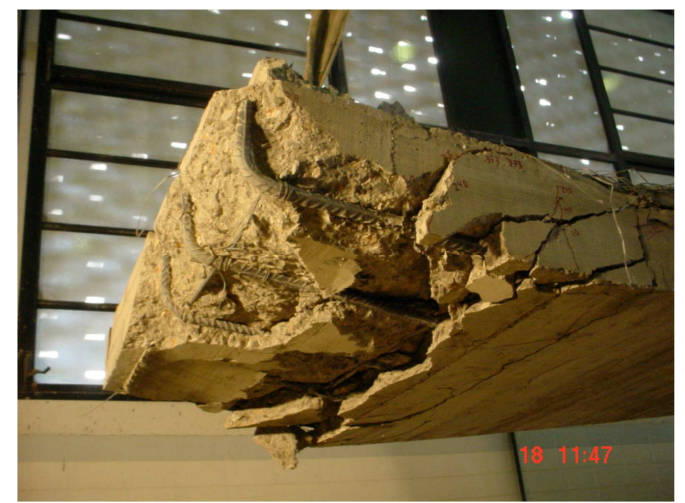

b) $1 \mathrm{I} / \mathrm{S} / 250 /$ t.r./B

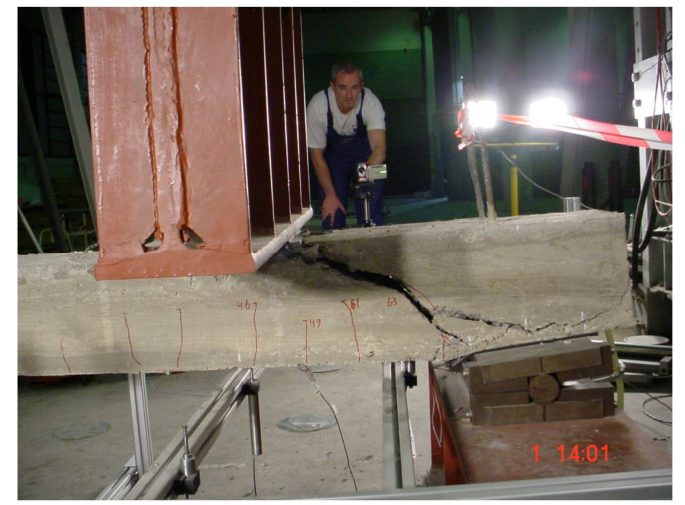

d) $\quad \mathrm{II} / \mathrm{B} / 65 /$ t.r./B

Figure 5: Series II specimens. Shear failure surfaces.

\subsection{Shear force at failure. Influence of longitudinal reinforcement spacing and of transverse reinforcement}

Table 2 summarises the shear force at failure and the shear stress at failure for Slabs I and II and the non-dimensional value of the ultimate shear force in relation to the ultimate shear force given by the EC2 (European Committee for Standardisation (CEN) 2002) to compare both series with different concrete batches and different ratios of the longitudinal bar spacing/depth. The EC2 shear formulation was considered because it offers very good correlations with the empirical results for these type of slabs, as demonstrated in section 5.3. The ultimate shear stress value was almost identical for slab I/S/119/t.r. (1.06 MPa) and the reference beam I/B/150/t.r. (1.02 MPa), showing a similar 
behavior when having a short bar spacing and transverse reinforcement, irrespective of the specimen width. The same trend was observed in slabs II/S/250/t.r./A and $B$ and beams II/B/65/t.r./A and B, for which an average ultimate shear stress value of 1.27 and 1.16 MPa was obtained, respectively. The ultimate shear stress of II/S/250/t.r./A and B was $1.27 \mathrm{MPa}$, which is higher than the value of $1.06 \mathrm{MPa}$ obtained for the slab with a lower bar spacing and transverse reinforcement (I/S/119/t.r). However, the slab with the highest bar spacing, $\mathrm{l} / \mathrm{S} / 316 /$ t.r., did not follow this trend and showed an ultimate shear stress of $1.13 \mathrm{MPa}$. Series I and Series II slabs did not differ, despite of the change in the support conditions.

The influence of the transverse reinforcement on the ultimate shear force cannot be quantified based on the experimental data available in this program. In the slab with a lower bar spacing $(1 / S / 119)$, the failure load was $14.5 \%$ lower when the slab contained transverse reinforcement. However, the transverse reinforcement increased the ultimate shear force by $8.6 \%$ for slabs $\mathrm{I} / \mathrm{S} / 316$.

Figure 6 shows the shear force per unit width versus the displacement at the load application point. The slabs with a short spacing between bars (I/S/119/t.r. and I/S/119/0) behave similarly to the reference beam I/B/150/t.r. Therefore, the width does not influence the shear stress at failure in this case. On the contrary, slabs with a large spacing between bars (I/S/316/t.r. and I/S/316/0) are less rigid, even though the internal steel reinforcement amount is almost the same. This effect is probably due to the lower tension stiffening effect when the bar spacing is larger because the amount of concrete that contributes in tension bonded to steel is less, as recognised by codes of practice. In addition, the transverse reinforcement only influenced the failure load and not the shear response, irrespective of the distance between bars.

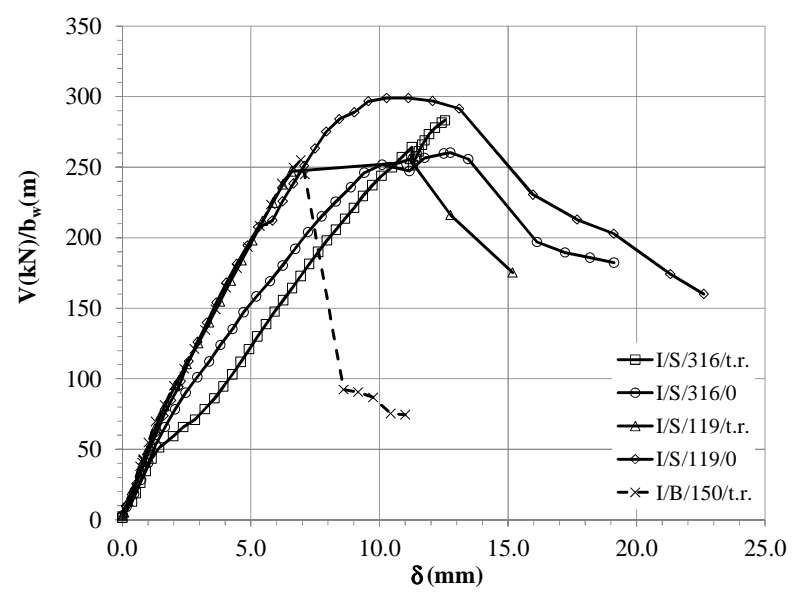

Figure 6: Series I specimens. Shear force per unit width vs. displacement at the load application point.

\subsection{Longitudinal reinforcement}

Figure 7 plots the strains of the longitudinal bars at the mid-width of the load application point. The strain profile of the slabs of Series II, which had an internal reinforcement of 
$\phi 20 \mathrm{~mm}$ spaced $250 \mathrm{~mm}$ and transverse reinforcement, is very similar to the slab of Series I, which had an internal reinforcement of $\phi 25 \mathrm{~mm}$ at $316 \mathrm{~mm}$ with transverse reinforcement. The specimens I/S/316/t.r., II/S/250/t.r./A and II/S/250/t.r./B had an almost identical $s / d$ ratio of 1.50 . The $s / d$ ratio for the remaining specimen (I/S/119/t.r.) was 0.54 . The presence of transverse reinforcement slightly increased the longitudinal strains irrespective of the bar spacing. In addition, both slabs without transverse reinforcement $(\mathrm{I} / \mathrm{S} / 316 / 0$ and $\mathrm{l} / \mathrm{S} / 119 / 0)$ showed a similar behaviour. The $b_{w} / d$ ratio $(8.0$ in slabs I and 5.5 in slabs II) did not significantly influence the longitudinal strains.

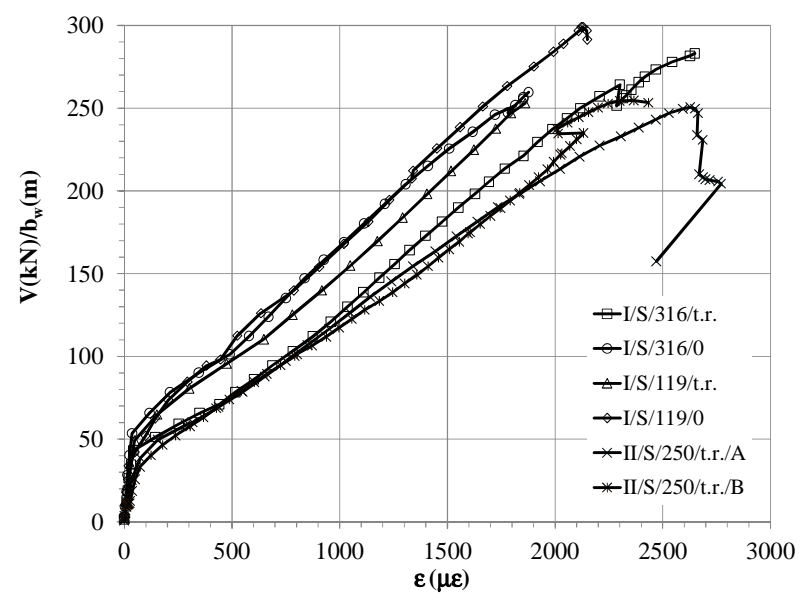

Figure 7: Shear force per unit width vs. strain at the longitudinal bars at the mid-width under the load application point for Series I and II.

The strains under the load application point are plotted in Figure 8 for one of the slabs of Series I with transverse reinforcement, to report the performance of a typical case. The strain gauges of the longitudinal bars are indicated as $L i$, where " $i$ " is related to the longitudinal bar location given by Figure 2. Irrespective of the bar spacing, the strain at the same slab section is very similar for all longitudinal bars.

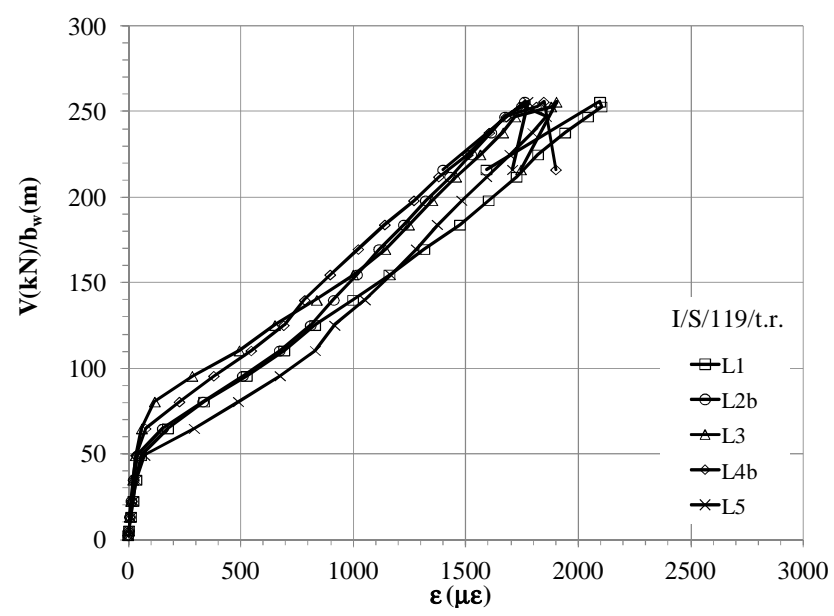

Figure 8: Shear force per unit width vs. strain at the different longitudinal bars under the load application point for slab I/S/119/t.r. 


\subsection{Transverse reinforcement}

As shown in Figure 9, the strain values of the transverse reinforcement were small and uniform for slabs with a short distance between bars. The strain gauges T1 and T3 of slab $\mathrm{I} / \mathrm{S} / 316 /$ t.r. and I/S/119/t.r. were placed at $486 \mathrm{~mm}$ and $535 \mathrm{~mm}$ from the mid-width, respectively, and the strain gauge $\mathrm{T} 2$ was at $169 \mathrm{~mm}$ and $59 \mathrm{~mm}$ from the mid-width, respectively (see location in Figure 2). The role of the transverse reinforcement is more significant in slabs with a large bar spacing because the strains reached values near 1700 $\mu \varepsilon$. This can be explained because the equilibrium of the three-dimensional strut and tie mechanism at the end of the slab width is reached due to the tensile force of the transverse reinforcement.
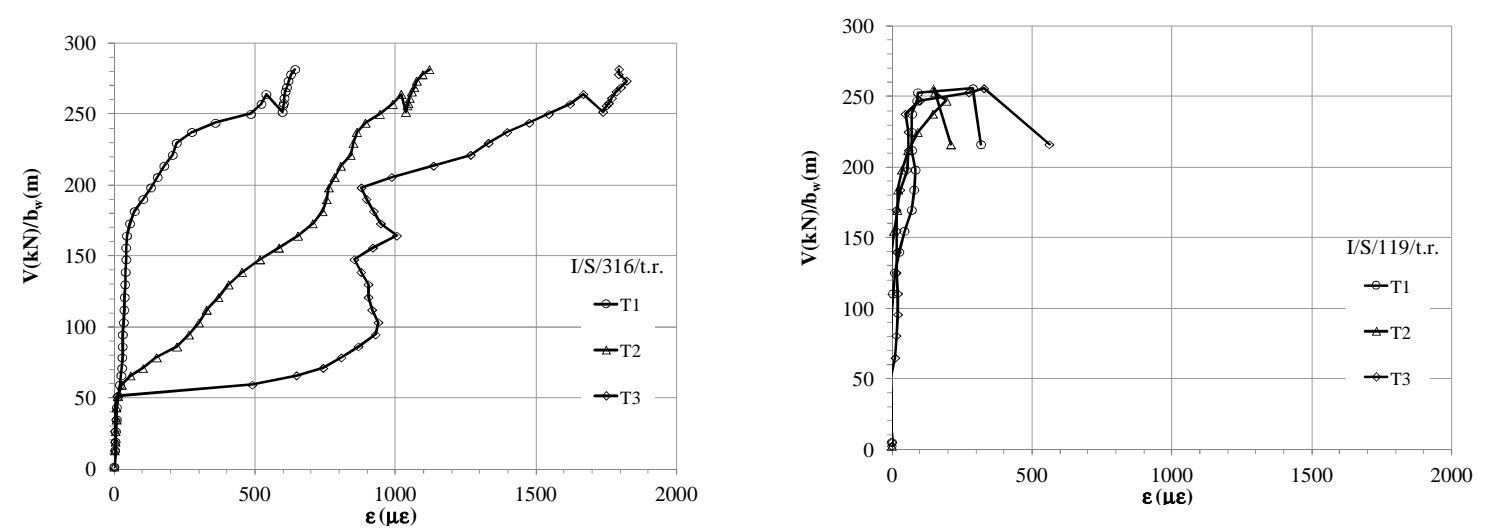

Figure 9: Strain at the transverse reinforcement at $300 \mathrm{~mm}$ from the support in $\mathrm{l} / \mathrm{S} / 316 / t . r$. and $\mathrm{I} / \mathrm{S} / 119 /$ t.r.

\section{ANALYTICAL STUDY BASED ON 79 SLAB TEST RESULTS}

\subsection{Database}

The database used for the analytical study was compiled using the six tests on concrete slabs carried out by Gurutzeaga that were presented in Sections 3 and 4 and 73 tests extracted from a published database (Collins et al. 2008). Only members that met the following criteria were selected from this database: $a / d \geq 2.5$, where $a$ is the shear span and $d$ is the effective depth; $b_{w} / d \geq 2$; and the failure of the beams was identified as shear failure. All involved experimental campaigns (Diaz de Cossio 1962, Kani et al. 1979, Leonhardt and Walther 1964, Lubell et al. 2004, Lubell et al. 2009, Regan and Rezai-Jorabi 1988, Richart 1948, Sherwood et al. 2006) have already been summarised in Section 2. As previously commented, the critical section is taken as being placed at a distance $d$ from the applied point loads and $d$ from the support of uniformly loaded specimens, as proposed in (Collins et al. 2008).

\subsection{Shear stresses at failure}

The failure shear stresses of the 79 slab specimens are presented in Figure 10, which shows the influence of the effective depth, $d$, the amount of longitudinal reinforcement, $\rho_{l}$ and the parameters $b_{w} / d$ and $s / d$, where $b_{w}$ is the breath of the web and $s$ the transverse 
spacing of the longitudinal reinforcement. Twenty-six specimens were excluded from this figure because the transverse spacing of the longitudinal rebar is not given in the references; these specimens all originated from Diaz de Cossio (1962) and Leonhardt and Walther (1964). The stresses given in Figure 10 have been normalised by considering the influence of the concrete compressive strength on the shear strength, as given in EC-2 or in reference Pérez et al. (2010).
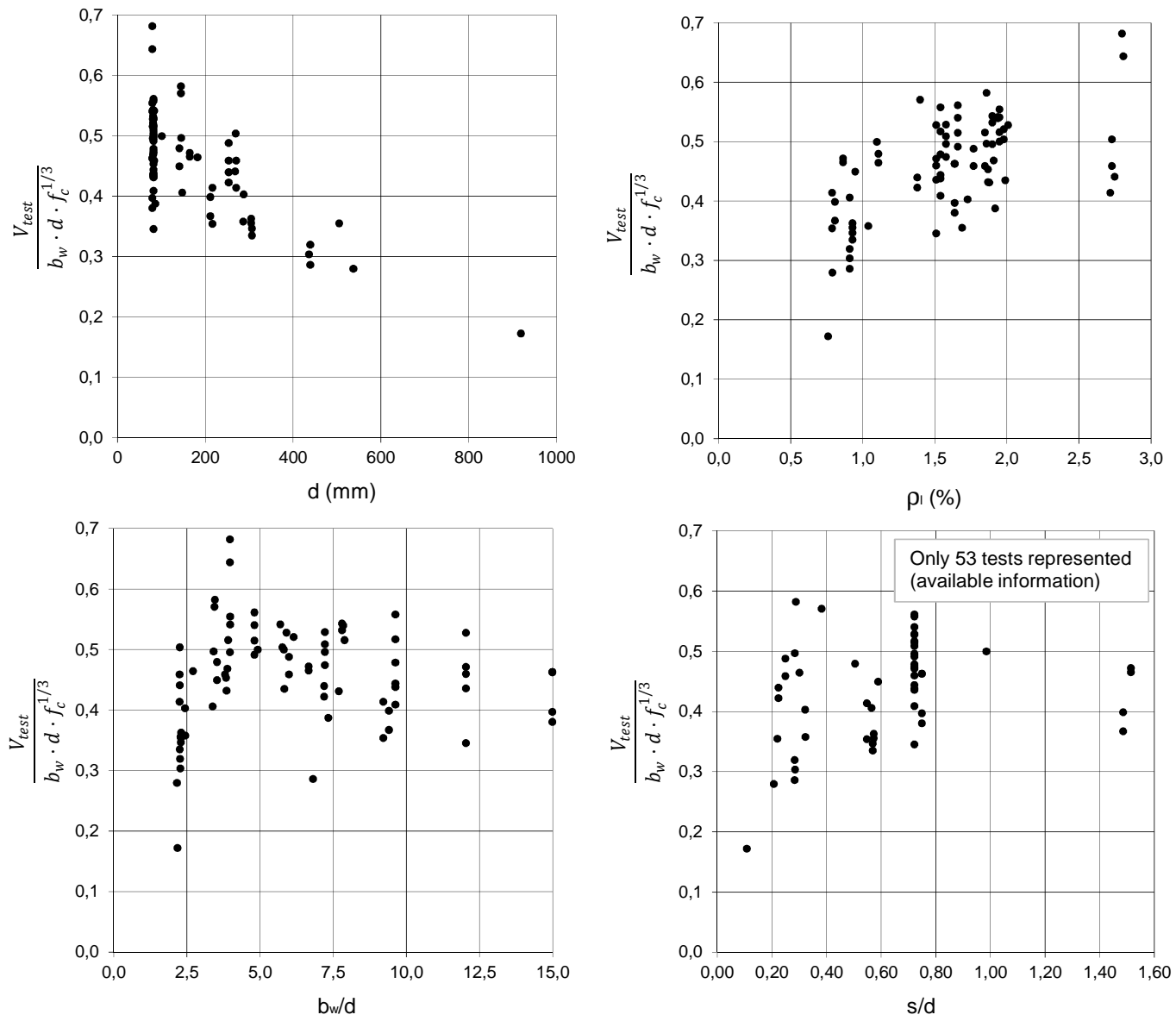

Figure 10: Normalised shear stresses for the 79 studied slabs.

Figure 10 shows that the size effect clearly influences the shear strength of slabs; the failure shear stress clearly decreased when the effective depth increased. The amount of longitudinal reinforcement also plays an important role on the shear strength of slabs without shear reinforcement; the shear stress significantly increased when the amount of longitudinal reinforcement increased. Conversely, parameters $b_{w} / d$ and $s / d$ did not have any clear influence. In next sections, the effect of the diameter and bar spacing of the longitudinal reinforcement as well as that of the bottom transverse reinforcement will be discussed. The influence of the parameter $b_{w} / d$ will not be commented on, as it did not seem to influence the parameters of interest, which confirmed previous findings (Kani et al. 1979, Lubell et al. 2004). However, it must be highlighted that recent published findings (Conforti et al. 2013) indicate that the $b_{w} / d$ ratio could influence the shear crack propagation, allowing a more stable response for elements with high values of $b_{w} / d$. The effect of the depth, the amount of longitudinal reinforcement and the maximum 
aggregate size may be found elsewhere (Lubell et al. 2009, Sherwood et al. 2006, Sherwood et al. 2007), as they are not the main focus of this paper.

\subsubsection{Diameter and bar spacing of the longitudinal reinforcement}

The relationship between the diameter of the longitudinal reinforcement and the bar spacing was studied based on 53 of the 79 test results because the necessary information was lacking from the remaining 26 test results. The longitudinal reinforcement did not exceed $2 \%$ in all 53 tests. Figure 11 a shows a reduction of the failure shear stresses when the diameter of the longitudinal reinforcement is increased, for subsets with $\rho_{l}$ lower or greater than $1 \%$.

a)

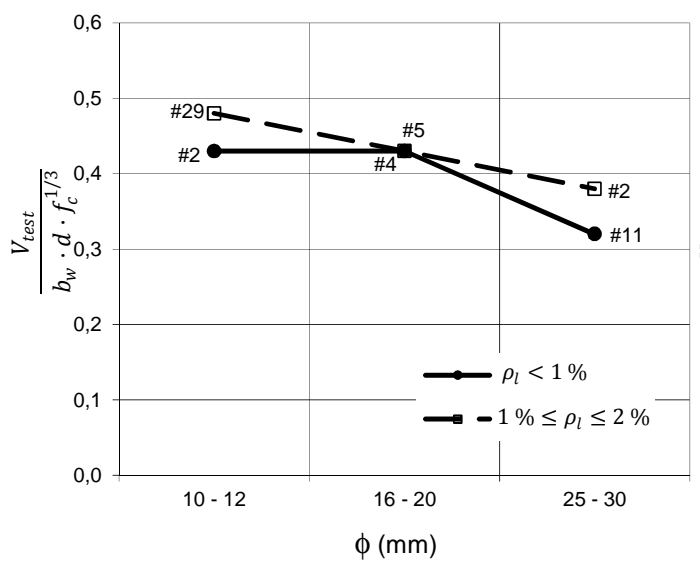

b)

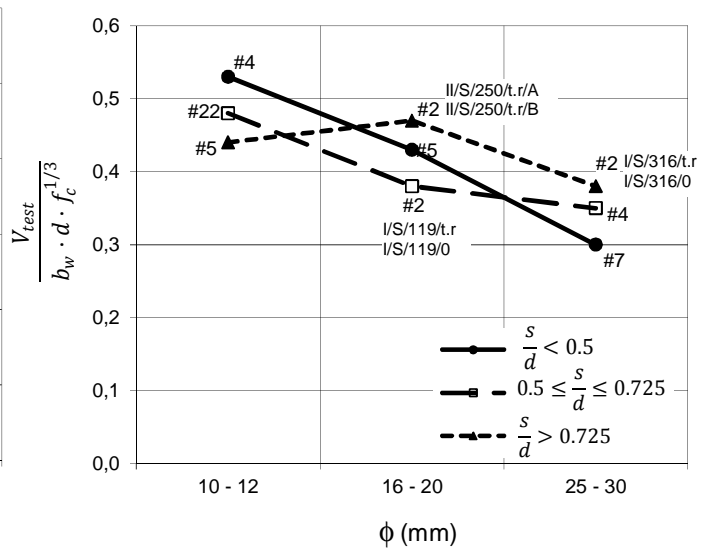

Figure 11: Normalised shear stresses for 53 specimens. Influence of the diameter of the longitudinal reinforcement vs the amount of longitudinal reinforcement and its transverse spacing.

Figure $11 \mathrm{~b}$ also shows the reduction on shear stresses when the longitudinal bar diameter is increased. However, the data included two subsets of outliers: the subset formed by two slabs with $\phi$ between 16 and $20 \mathrm{~mm}$ and $s / d$ greater than 0.725 (slabs II/S/250/t.r/A and $\mathrm{II} / \mathrm{S} / 250 / \mathrm{t} . \mathrm{r} / \mathrm{B}$ ) and the subset formed by two slabs with $\phi \geq 25 \mathrm{~mm}$ and $s / d$ greater than 0.725 (slabs $\mathrm{I} / \mathrm{S} / 316 /$ t.r and $\mathrm{I} / \mathrm{S} / 316 / 0$ ). For these four slabs, the actual $s / d$ factor was approximately 1.5 , as they were the four slabs with the greater bar spacing tested by Gurutzeaga (Gurutzeaga-Zubillaga 2006). Conversely, the other two slabs tested Gurutzeaga (Gurutzeaga-Zubillaga 2006) (slabs I/S/119/t.r and I/S/119/0) followed the general trend. As shown in Section 4.1, the shear failure was irregular and curled for the four slabs that did not follow the general trend (Figure $4 a, 4 b$ and Figure $5 a, 5 b$ ). This surface failure could be explained by the formation of a three-dimensional resisting mechanism created by the struts, which are inclined to reach the longitudinal reinforcement, generating a three-dimensional state of stresses in the uncracked compression zone. Shear models that take into account the stresses in the un-cracked 
compression zone and the shape of the critical crack could probably be adapted to take into account this phenomena, for example the models by Park et al. (2013) and Marí et al. (2014) among others. Moreover, this three-dimensional effect could increase the failure area and the aggregate interlock effect.

Although Figure 11 shows the influence of the longitudinal reinforcement, the observed reduction is also related to the size effect, as shown in Figure 12. Most slabs with small diameter bars had a low mechanical depth. Conversely, slabs with longitudinal bars $\phi \geq 25$ $\mathrm{mm}$ presented a $d$ greater than $300 \mathrm{~mm}$. Nevertheless, as can be seen for the 3 subsets of slabs with $150 \mathrm{~mm} \leq d \leq 300 \mathrm{~mm}$, the reduction of shear stresses at failure with the increase of the bar diameter exists, although the influence of the bars was not as significant as that predicted by Figure 11, as indicated by the three subsets of slabs with $150 \mathrm{~mm} \leq d \leq 300 \mathrm{~mm}$.

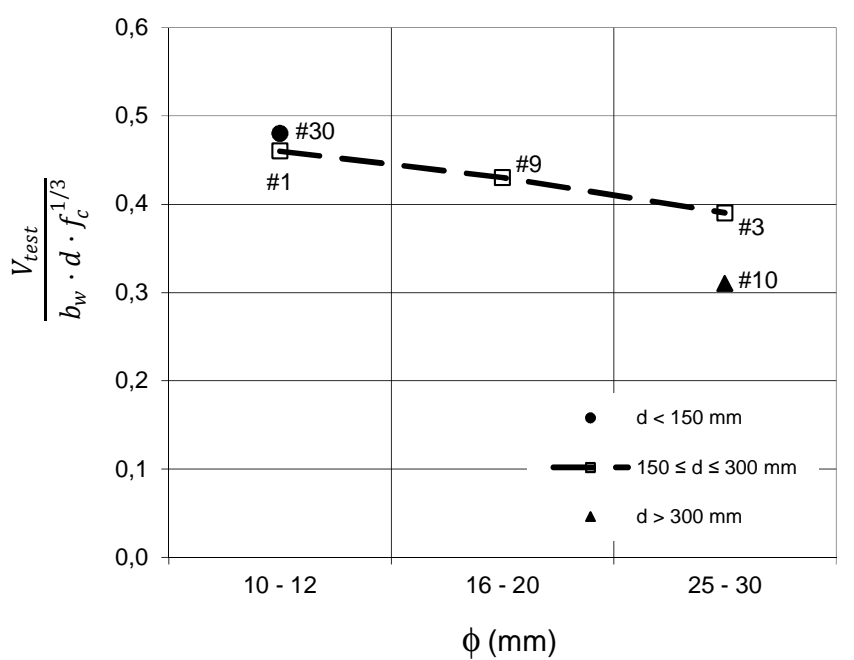

Figure 12: Normalised shear stresses for 53 specimens. Size effect and influence of the diameter of the longitudinal reinforcement.

\subsubsection{Bottom transverse reinforcement}

Figure 13 shows that the bottom transverse reinforcement does not influence significantly the shear stresses at failure for all the beam tests included in the database. The given trend lines for the subsets of slabs with transverse reinforcement and without transverse reinforcement are very similar. It would seem reasonable to think that the influence of bottom transverse reinforcement mainly depend on the values of $s / d$. However, Figure 14 shows that information on the parameter $s / d$ was only available for five slab specimens without transverse reinforcement. Thus, conclusions cannot be drawn. 

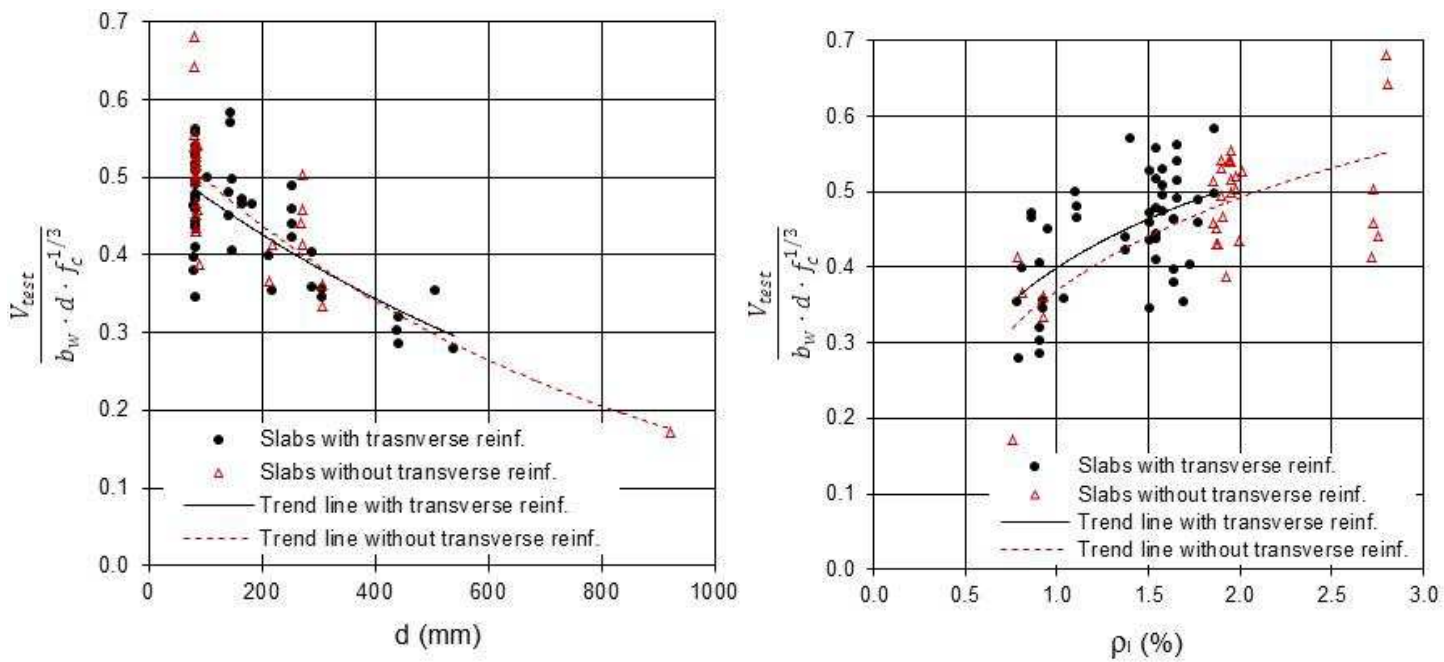

Figure 13: Normalised shear stresses for the 79 studied slabs. Influence of the bottom transverse reinforcement.

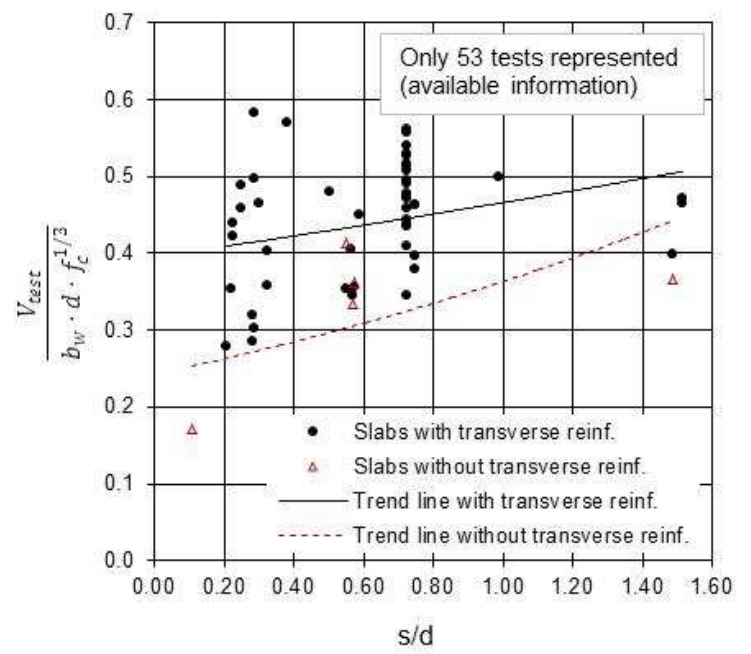

Figure 14: Normalised shear stresses for 53 slabs. Influence of the bottom transverse reinforcement and the longitudinal bar spacing.

\subsection{Shear strength predicted by the shear design procedures}

Table 3 presents the adjustment of the different shear procedures presented in Section 2.1 for the 79 slab tests. The shear procedures from ACl Code 318-08 (equation 11-3 or equation 11-5) offered the worst correlation with the empirical results. Conversely, the results obtained by Eurocode 2, Model Code 2010 (Level II of approximation) and the optimised equation GP-4 (Pérez et al. 2010) offered the best correlations. Specifically, the latter approach resulted in the smallest standard deviation. The adjustment of the Model Code 2010 (Level II) is good, but it is slightly conservative for the 5th percentile of the $V_{\text {test }} / V_{\text {pred }}$ ratio of 1.09. The Level I approximation of the Model Code 2010 is probably too conservative for this set of elements. 
The equation GP4 was derived from the EC-2 shear formulation using a genetic programming algorithm (Pérez et al. 2010). The beam and slab specimens from the same published database (Collins et al. 2008) were used. Therefore, Table 3 also presents the adjustment of the different shear procedures for the 52 slab tests that were not used in the GP-4 optimisation procedure (in brackets). The eliminated 27 slabs tests were used in the optimisation. Therefore, the global comparison could be considered unfair.

Nevertheless, the adjustment for the 52 tests (numbers in brackets for the average, standard deviation and (OV) is very similar to that of the complete slab database with 79 test results, as shown in Table 3.

\begin{tabular}{lcccccc}
\hline \multicolumn{1}{c}{$\mathbf{V}_{\text {test }} / \mathbf{V}_{\text {pred }}$} & EC-2 & $\begin{array}{c}\text { GP-4 } \\
\text { (Pérez et al. 2010) }\end{array}$ & ACl 11-3 & ACl 11-5 & $\begin{array}{c}\text { MC10 } \\
\text { Lev. I }\end{array}$ & $\begin{array}{c}\text { MC10 } \\
\text { Lev. II }\end{array}$ \\
\hline Average & 1.14 & 1.18 & 1.54 & 1.47 & 1.88 & 1.35 \\
& $(1.14)$ & $(1.20)$ & $(1.51)$ & $(1.45)$ & $(1.85)$ & $(1.36)$ \\
\hline Median & 1.13 & 1.20 & 1.56 & 1.51 & 1.87 & 1.35 \\
\hline \multirow{2}{*}{ Standard Deviation } & 0.14 & 0.13 & 0.32 & 0.28 & 0.30 & 0.17 \\
& $0.13)$ & $(0.12)$ & $(0.31)$ & $(0.27)$ & $(0.28)$ & $(0.15)$ \\
\hline \multirow{2}{*}{ CoV (\%) } & 12.10 & 11.25 & 20.83 & 19.00 & 16.12 & 12.84 \\
& $(11.44)$ & $(10.23)$ & $(20.57)$ & $(18.55)$ & $(15.28)$ & $(11.14)$ \\
\hline Minimum & 0.71 & 0.84 & 0.51 & 0.51 & 1.08 & 0.84 \\
\hline ( $\left.\mathbf{V}_{\text {test }} / \mathbf{V}_{\text {pred }}\right)_{5 \%}$ & 0.93 & 0.94 & 1.01 & 1.00 & 1.47 & 1.09 \\
\hline Maximum & 1.50 & 1.42 & 2.32 & 2.07 & 2.71 & 1.75 \\
\hline ( $\left.\mathbf{V}_{\text {test }} / \mathbf{V}_{\text {pred }}\right)_{95 \%}$ & 1.36 & 1.39 & 1.95 & 1.85 & 2.35 & 1.66 \\
\hline
\end{tabular}

Table 3. Verification of the different Codes of Practice for the database with 79 tests. In brackets, verification for the database with 52 tests not used in the GP4 formula derivation.

Table 4 presents the $V_{\text {test }} / V_{\text {pred }}$ results for the different analysed experimental campaigns. The predictions using the different formulations of the tests presented in this paper have a Coefficient of Variation on the average with respect the other experimental campaigns. However, the mean value of the ratio $V_{\text {test }} / V_{\text {pred }}$ is higher than the average for several procedures, especially for EC-2 and GP-4 equations, which generally offer the best predictions. This discrepancy could explain why the 4 beams discussed in Section 5.2.3 (Figure 11) did not follow the general trend.

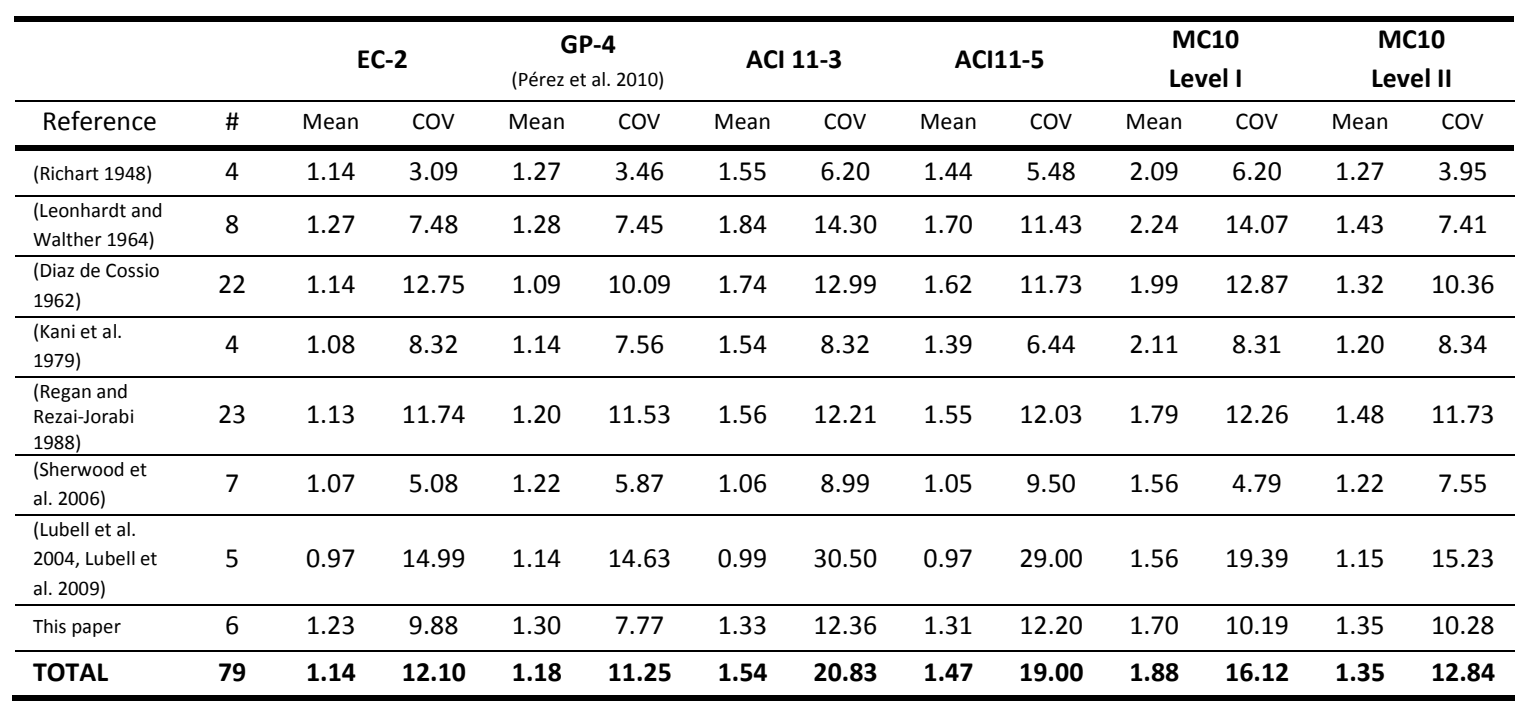

Table 4. Verification of the different Codes of Practice for subsets of the database. 


\section{CONCLUSIONS}

This paper concerns the shear strength of one-way concrete slabs. An experimental program was performed to study the influence of the spacing of the longitudinal reinforcement bars and the influence of transverse reinforcement. The obtained experimental results were compared to the results of 79 tests performed by other authors and to the theoretical predictions given by different shear design procedures. The following conclusions can be drawn from the present study:

- The experimental program performed by the authors consisted of two series of one-way slabs and beams with similar longitudinal reinforcement ratios. The spacing of the longitudinal bars and the existence, or not, of bottom transverse reinforcement have been analysed. This experimental program confirms that the width and the bottom transverse reinforcement did not significantly modify the shear response of the slab as has been commented from the literature review presented in this paper.

- As observed in the experimental program, the shear failure surface was quasicylindrical and uniform along the web breadth in the slabs with a short longitudinal bar spacing and in the beams. On the contrary, the shear failure was irregular and curled with bumps in and out along the web breadth in the slabs with a large longitudinal bar spacing ( $s / d$ of approximately 1.5 ) due to the three-dimensional resisting mechanism formed by the struts, which are inclined to reach the longitudinal reinforcement, generating a three-dimensional state of stresses in the uncracked compression zone. Moreover, this mechanism may increase the aggregate interlock effect. However, this effect cannot be conclusively confirmed with the available data.

- Slabs with a large longitudinal bar spacing show a less rigid load-deformation behaviour, probably due to the reduction in the tension stiffening effect caused by the lower area of concrete that contributes to tension.

- A database of 79 slab tests was analysed. The analysis of the database confirms that the transverse reinforcement does not influence the shear stresses at failure. A clear conclusion on the effect of the parameter $s / d$ could not be extracted from this database, and more experimental tests should be carried out.

- Finally, different shear procedures were applied to predict the shear failure load of the slabs compiled in the database. The $\mathrm{ACl} 318-08$ offers the worst correlation with the empirical results. The best predictions are given by the Eurocode 2, the Model Code 2010 (level II) and the formulation by Perez et al. (2010), which was obtained using a genetic programming algorithm. This latter approach resulted in the smallest standard deviation. 


\section{ACKNOWLEDGEMENTS}

This work was supported by the Spanish Ministry of Science and Technology (MAT200200615, BIA2007-60197, and BIA2009-11764).

\section{REFERENCES}

ACl Committee 318 (2008) Building Code Requirements for Structural Concrete (ACl 31808) and Commentary. American Concrete Institute, Farmington Hills, MI, USA

Collins MP, Bentz EC, Sherwood EG (2008) Where is shear reinforcement required? review of research results and design procedures. ACI Struct J 105:590-600

Conforti, A., Minelli, F. and Plizzari, G. (2013) Wide-shallow beams with and without steel fibres: A peculiar behaviour in shear and flexure. Composites Part B (Engineering) 51:282290

Diaz de Cossio R (1962) Discussion on shear and diagonal tension. J.Am.Concr.Inst 59:1323-1332

European Committee for Standardization (CEN) (2002) Eurocode 2: Design of Concrete Structures: Part 1: General Rules and Rules for Buildings. European Committee for Standardization

Fédération Internationale du Beton (2012) Model Code 2010, Final Draft. Fédération Internationale du Beton

Gurutzeaga-Zubillaga M (2006) Resistencia a esfuerzo cortante de losas unidireccionales de hormigón armado. Dissertation or Thesis, Departament d'Enginyeria de la Construcció; Universitat Politècnica de Catalunya

Kani MW, Huggins MW, Wittkopp RR (1979) Kani on shear in reinforced concrete. Dept. of Civil Engineering, University of Toronto

Kragh-Poulsen J, Hoang LC, Goltermann P (2011) Shear capacity of steel and polymer fibre reinforced concrete beams. Mater Struct 44:1079-1091

Leonhardt F, Walther R (1964) The Stuttgart Shear Tests, 1961

Lubell A, Sherwood T, Bentz E, Collins M (2004) Safe shear design of large, wide beams. Concr Int 26:66-78

Lubell AS, Bentz EC, Collins MP (2009) Influence of longitudinal reinforcement on one-way shear in slabs and wide beams. J Struct Eng 135:78-87

Marí A, Cladera A, Oller E, Bairán J (2014). Shear design of FRP reinforced concrete beams without transverse reinforcement. Compos Part B: Eng 57:228-41. 
Minelli F, Conforti A, Cuenca E, Plizzari G (2013) Are steel fibres able to mitigate or eliminate size effect in shear?. Mater Struct:1-15

Park H, Kang S, Choi K. (2013) Analytical model for shear strength of ordinary and prestressed concrete beams. Eng Struct 46:94-103.

Pérez JL, Cladera A, Rabuñal JR, Martínez-Abella F (2012) Optimization of existing equations using a new Genetic Programming algorithm: Application to the shear strength of reinforced concrete beams. Adv Eng Software 50:82-96

Pérez JL, Cladera A, Rabuñal JR, Abella FM (2010) Optimal adjustment of EC-2 shear formulation for concrete elements without web reinforcement using Genetic Programming. Eng Struct 32:3452-3466

Regan P (1993) Research on shear: a benefit to humanity or a waste of time?. Struct Eng 71:337-337

Regan PE, Rezai-Jorabi H (1988) Shear resistance of one-way slabs under concentrated loads. ACI Struct J 85:150-157

Richart FE (1948) Reinforced concrete wall and column footings (part II) 45:237-260

Sherwood EG, Bentz EC, Collins MP (2007) Effect of aggregate size on beam-shear strength of thick slabs. ACI Struct J 104:180-190

Sherwood EG, Lubell AS, Bentz EC, Collins MP (2006) One-way shear strength of thick slabs and wide beams. ACI Struct J 103:794-802 


\section{Table captions}

Table 1. Summary of the shear design formulations used in this paper.

Table 2. Specimen properties and test results.

Table 3. Verification of the different Codes of Practice for the database with 79 tests. In brackets, verification for the database with 52 tests not used in the GP-4 formula derivation.

Table 4. Verification of the different Codes of Practice for subsets of the database. 


\section{Figure captions}

Figure 1: Test setup for Series I and II.

Figure 2: Test setup for Series I elements. Units in $\mathrm{mm}$.

Figure 3: Test set-up for Series II elements. Units in $\mathrm{mm}$.

Figure 4: Series I specimens. Shear failure surfaces. a) I/S/316/t.r; b) I/S/316/0; c) I/S/119/t.r.; d) I/S/119/0; e) I/B/150/t.r.

Figure 5: Series II specimens. Shear failure surfaces. a) II/S/250/t.r./A; b) II/S/250/t.r./B; c) II/B/65/t.r./A; d) II/B/65/t.r./B.

Figure 6: Series I specimens. Shear force per unit width vs. displacement at the load application point.

Figure 7: Shear force per unit width vs. strain at the longitudinal bars at the mid-width under the load application point for Series I and II.

Figure 8: Shear force per unit width vs. strain at the different longitudinal bars under the load application point for slab I/S/119/t.r.

Figure 9: Strain at the transverse reinforcement at $300 \mathrm{~mm}$ from the support in I/S/316/t.r. and I/S/119/t.r.

Figure 10: Normalised shear stresses for the 79 studied slabs.

Figure 11: Normalised shear stresses for 53 specimens. Influence of the diameter of the longitudinal reinforcement vs the amount of longitudinal reinforcement and its transverse spacing.

Figure 12: Normalised shear stresses for 53 specimens. Size effect and influence of the diameter of the longitudinal reinforcement.

Figure 13: Normalised shear stresses for the 79 studied slabs. Influence of the bottom transverse reinforcement.

Figure 14: Normalised shear stresses for 53 slabs. Influence of the bottom transverse reinforcement and the longitudinal bar spacing. 